\title{
The Inheritance of the Hui Nationality Tajiao
}

\author{
Junping Yang \\ North Minzu University, Yingchuan, Ningxia, 750021
}

\author{
Keywords: Hui Nationality Tajiao, Inheritance, Dance
}

\begin{abstract}
Hui is the Muslim people of Islam from the Tang Dynasty, because the guidance of people's daily entertainment is more barren. With the body cultural characteristics of the "foot" project experienced flourishing and development, now has tended to disappear. Inheritance is imminent, rescue without delay. Choose the form of dance as a carrier of inheritance, to dance ecology theory and anthropological observation method as the support, the use of college classroom teaching attributes will be "foot" of the Hui's body culture phenomenon to the most primitive of the most essential ecological in. To make up for the lack of traditional preservation, protection and inheritance in the process of urbanization, so as to make the folk dance teaching of the Hui ethnic group become the theoretical basis of the important applied scientific research achievements.
\end{abstract}

\section{Introduction}

On the Hui Nationality Tajiao must first introduce the distribution in the northwest region of Ningxia Hui nationality. The Hui people are few, the earliest from the beginning of the Tang Dynasty is the people believe in Islam. It is a nation that guides and regulates daily life entirely with Islamic religious beliefs. This nation believes in "Allah - Allah". Worshiping another world created by Allah 's use of light - "Miao Shi". In the consciousness of the people of the Hui people that their actions can see the Lord can see. To insist on doing good deeds from God to discuss "mouth" and to extend their supreme to give a positive "life".

The first of the footsteps originated in the Han and Tang dynasties. Was introduced from the Western Regions into a Chinese attack and defense martial arts, was originally a businessman to go out to do business in order to self-defense and a set of martial arts specializing in leg law, in the Song Dynasty to flourish. As the Qing Dynasty repression of the Hui uprising, Shaanxi Weinan area of the Hui exile will be treaded to the Jingyuan County village village, and later by the martial arts fighting evolved into the local Muslims slack free time to send the spirit of the tool. Has gradually become the Jingyuan local Hui people learn from each other, Johnson \& Johnson fitness sports project, and after a period of evolution, and gradually this event into local large-scale sports athletics essential to the performance of the project. Later, it is by the local people engaged in mass cultural work of their processing organizations to the stage, developed into a set of sports performances and competitive competition in one of the characteristics of the project. It is began in the beauty of the initial pursuit, focusing on its uniform clothing, music with the stage formation changes. The

In 1985, the Ministry of Culture, the State Ethnic Affairs Commission and the China Association for Democracy and People's Livelihood jointly launched the "three sets of integration of folk literature". At that time the relevant experts in the Northern Song Dynasty famous painter Ma Yuan's "tread song" found in the description of Long people on foot entertainment scene information. It is said that it is regardless of men and women, is the time when the slack villagers in order to entertain everyone organized to play with each other for a long time to play. People in the fields with each other on the form of trample each other, farmers set up their own rules to choose the bucket of the winning or losing, as a pleasant physical and mental, improve spiritual life. And only in Jingyuan County perfume town garden village among the farmers also spread. After a large number of census and historical data also found that the country was only Ningxia Jingyuan County Village also spread this Hui folk activities, other places have been basically disappeared. This 
"women" to participate in the foot project even more rare.

The formation of the foot is completely between the men of a fun activity, it is extreme, intense forms of activities. And even in some cases there will be some skin and even physical damage. And women elegant, delicate gender characteristics or lifestyle will be some contradictions. So those girls are not involved in the period of those game activities. Women's words and deeds are relatively conservative, restrained, happy expression and excitement most of the mood will not use exaggerated body language or do not use dance to express. This is in the concept or behavior mode with the foot of such a large dynamic activities has more or less conflict. And with generations of people in the understanding and expression of the changes in the way of life and living environment changes and the lack of fun activities so that part of our young Hui peasant women from the ideological began to accept 'pedal' this simple, easy Of the entertainment sports. And after a period of development they are gradually involved in them, the farmer came down in the middle of friends and family to find some simple fun. So, there are women involved in the tread of the game activities gradually formed. And even the development of the late, women participate in the performance of the foot form frequently appeared.

In Jingyuan County village village "foot" has been circulating nearly a hundred and seventy years. And after it gradually became a sporting event, the local mosque has gradually joined the women's athletic performance. Which, joined the composition of the game, began to pay attention to the game between men and women in the foot. In the arena regardless of men and women, dozens of Hui Nationality Tajiao players two groups of a side kick kick. For a while, the players will be companions side frame in the shoulder, out of the legs on the step; for a while, one-on-one jump feet empty legs. Pedal hardness and softness, there is a strong competitive and performance.

From the Ningxia Jingyuan County Cultural Center, it is to collect and sort out the "folk dance - Jingyuan County data book" in a book. Pedal like playing football, with the foot without hand. And traditional Chinese martial arts in the leg method are different. Foot requirements are complete lower limb movements, is the active offensive between the legs and feet. It is must be full-foot force, mostly hook dynamic. Only allowed to pedal, kick, sweep. Not allowed to play with the toes, but not allowed to hand to play, push, pull. In the form: one person to one person, one person to a few people, but also two people on the two, two of the four, many people on the crowd on the tread and so on. In the way: the two sides on the tread when you follow me flash, you attack me keep the principle. The basic action is divided into flat tread, broken feet, back foot, ring turn, after the turn, flying feet, and so on 36 kinds of moves. Ping tai general sideways to face each other, with the whole foot to the opponent pedal out. Broken feet, will have to jump one leg, in the face of opponents positive, to the high pedal out. Back foot, Hui folk commonly known as "off the back door", used to attack each other's crotch, buttocks. This action sound east hit the West, very hard to prevent, usually in the back to the opponent, suddenly out to the rear. Rotate, that is, fast swivel 360 degrees, against the opponent's back and side. Flying feet, that is, legs vacated, stepped on the other side of the shoulder and back. In the tread, often one or two action works together, as a whole action. During the game, the venue is 10 meters X10 meters, flat and spacious. Do not wear shoes and other hard shoes, are not allowed to use the head, fist, elbow, arm attack each other.

In the nineties more and more cultural people realize that this is not only a local people's recreational activities, more important is to return to the national unique folk culture, but also reflects the local Hui people simple and honest attitude. From which it jumps high, fast, sweep away, turn fast, stand firm these dynamic requirements of the tread is not difficult to find the local people positive and optimistic attitude towards life. We all know that all the art comes from life plus imagination, then, both life and performance, through the dance art workers to explore the finishing can be completely from the tread action to find one of the dance. Therefore, the development of foot into a dance is an inevitable trend, and the force of women's foot Ningxia Hui folk dance development and inheritance is imperative. It should be more and more Muslim dance researchers pay attention to, and gradually organize the development of the characteristics of its dance performances, to assume the responsibility of the way of dance. Only this high degree of attention will make more than a thousand years ago from the Western Regions rooted to the Chinese Ningxia 
Hui tribe inheritance carry forward, become only the Hui folk dance.

\section{The Traditional Dance of the Hui People Calls for the Later People}

Initially, by the Jingyuan County Cultural Center is responsible for finishing out the most dancing of the square competition project "step foot dance." The middle of the 24 selected actions in the conscious increase in their ornamental. In 1987, in the regional national sports, the foot dance was classified as martial arts sports show project. Also during this period through their years of activities to sum up, there was the king of the foot, "Ma Junwen." This can also be said to be a milestone in the form of "foot dance".

And many non-material cultural heritage projects, foot is now facing the disappearance of the crisis, and "women's foot" even more so. In terms of the cultural heritage of ethnic minorities, the situation of the development of the primitive culture of the Hui nationality is concerned, and the introduction of a practical classroom teaching material which is compatible with the theory of the Hui nationality. Northern Nationalities University is located in the only ethnic minority areas of the Hui nationality - Ningxia, is a national ethnic group under the national characteristics of institutions, our school in the art school to pursue the characteristics of Hui is inevitable, our school Hui dance teaching to become our district dance school A major feature and highlight is the inevitable trend of development. But so far, in the school of art teaching class especially dance, our school's Hui characteristics are still in the bottleneck stage, the national characteristics are not clear, the lack of artistic typical. Can not be like Tibetan, Uygur dance formation system is widely used and recognized as a variety of art institutions in the national art teaching compulsory course. The reason is the lack of a set of practice and theory of supporting the application of teaching materials. Over the years, the region on the middle of the arts institutions Ye Hao, art groups are also in the intermittent launch of the Hui "tread" finishing work, but are short-lived. There are some sort of scattered material also can not be a true sense of the teaching of ecological chain to use in teaching. "Foot" dance materials from the project to promote such a specific and effective implementation process will be Ningxia University Hui dance school contribution to the power. Its meaning lies in the form of dance teaching to sort out the typical Tibetan culture and memory of the Hui, the implementation of the "foot teaching materials" and the development of teaching materials to expand the classroom application and teaching promotion will be completed on the foot of this folk culture the most fundamental heritage.

70, 80 years, pedal is still Jingyuanyuan village popular, almost everyone will every day after dinner, the villagers are in droves to the production team in the game. There will be 870 people who will perform "treadmill" on the ground, among them, 451 are young adults between the ages of 20 and 50. As a result of intense funding, Jingyuan did not set up a professional treadmill performance team, whenever there are important performance tasks, they will be working in the field of the villagers to recall, and so on after the show they re-find a job again. Garden village of the predecessors said, 23 years ago, he participated in the excavation foot, casually into the village, greeted the villagers, some people came out to practice. However, in the past 15 years, the villagers in the Xihaigu area have gone out to work in large numbers, and the concept of busy farming and slackness has been diluted. Even ten people have gathered together to learn the skills of the footsteps. As the foot dance is a group of dance, no dance records, and now, only in some special collective performances or athletics can learn. As the times change the time will be less and less, the rescue without delay!

\section{Tajiao Dance Rescue and Excavation has Long Way to Go}

In 2004, the foot dance was the Ministry of Culture as the second batch of Chinese folk cultural project pilot project. Jingyuan County to protect this unique Islamic culture in the world through the release of poverty alleviation cattle, relief funds, in some primary and secondary schools to set foot training courses and other forms but it is difficult to implement. As a result of foot dance, after all, there is a certain competitive, and primary school students self-control is very poor, slapstick blood 
will certainly happen, interest is not easy to cultivate. While the students on the course of tension, learning enthusiasm is not high, more difficult to popularize. This has emerged a kind of inheritance without object, inherited the environment without the environment. And this urgency is caused by many reasons. Regardless of the inheritance itself or the inheritance process, in the present seems to its environment and the choice of the object to analyze the dance higher education teaching heritage itself is a teaching and learning process, and this repeated practice of the process has become the basis of the spread of foot The Therefore, the higher education teaching classroom for the completion of the succession of the existence of favorable conditions.

"Treads" in the experience from the no, and then to, and then to the verge of disappearing such a historical process, until now people or art workers should be a strong sense of Hui Nationality Tajiao urgent need to rescue, women tread It is necessary to rescue. A culture of deep excavation, is not a matter of time. Inheritance must develop, however, in a period of history of the interpretation and history of this review and thinking after the practice of dance form is the most practical but also the most reliable inheritance. The key to this work lies in the emergence of a complete set of comprehensive theoretical and classroom time materials, that is, the establishment of "pedal teaching materials." To pedal theory and practice the effective establishment of textbooks to inherit; It is the most direct and effective way to pass the popularization of classroom practice and teaching and research.

\section{References}

[1] Qiu Shusen. "Chinese Hui literature." Ningxia People's Publishing House

[2] Zhong Yajun Wang Ning. "Introduction to Hui Folk Literature." Ningxia People's Publishing House. 2013. 9 